To cite: Arora, P. (2012). The folksong jukebox: Singing along for social change in rural India, Asian Journal of Communication, 22(4), 337-352.

\title{
The folksong jukebox: Singing along for social change in rural India
}

\author{
Payal Arora \\ Department of Media and Communication \\ Erasmus University Rotterdam, The Netherlands \\ Web: $\underline{w w w}$.payalarora.com \\ Email: arora@eshcc.eur.nl
}

\begin{abstract}
In designing digital literacy content for marginalized demographics, we need to garner local resources to structure engaging and meaningful media experiences. This paper examines the socio-cognitive implications of a novel edutainment product in rural India on learning, stemming from an e-development initiative funded by Hewlett Packard. This product encapsulates a multiplicity of media forms: text, audio and visual, with social-awareness folk themes endemic to the locality. It uses the karaoke 'Same-Language-Subtitling' feature that won the World Bank Development Marketplace Award in 2002 due to its simple yet innovative application that has proven to have an impact on reading skills. The product strives to combine cultural regeneration, value-based education, incidental literacy and language practice through entertainment. The paper investigates how this product addresses engagement and empowerment simultaneously, based on elements such as emotional appeal, multimodal stimulation, interactivity, contextual content and local representation. This is useful for practitioners and scholars interested in the design of novel edutainment content for international, underrepresented demographics.
\end{abstract}

Key Words: edutainment, media literacy, karaoke, folksongs, same language subtitling, empowerment, digital content, India

\section{Introduction}

Over these years, the term 'digital divide' has evolved beyond the defined gap between those that have access to technologies and those that do not (Carvin, 2000; Lemke \& Coughlin, 1998;

Solomon et al., 2003). Of particular concern to mitigating this divide is about focusing on how people use these technologies to generate and consume digital content. To best capitalize on prevailing technologies, it is essential to have high quality, meaningful, culturally responsive and 
linguistically appropriate content as well as the opportunity to participate in its generation (Taglang, 2000). Warschauer (2003) states that, "the key issue is not unequal access to computers but rather the unequal ways that computers are used" (p. 47). In fact, there is some excellent and accessible media content out there, some of which have been around for some decades. For example Sesame Street, the classic children's television show manages to engage a vast and global populace due to its ready embrace of multiple languages, and cultures and emphasis on entertainment. In Sao Paulo in Brazil, a local coalition Sampa facilitates the online sharing of music files with community-based themes between hip hop bands and their listeners. Harlem Live, another interesting digital resource for economically disadvantaged African Americans in New York, fosters technological participation through the arts. Online projects such as Think Quest and Creative Commons serve as critical portals for content sharing and collaborative learning. However, for the most part, the bulk of interactive media fail to target populations in rural areas, especially in developing countries where engaging and sociallymeaningful content is much needed (Cocking \& Greenfield, 1996). In fact, current dominant content can serve as a significant barrier to access by privileging select languages, cultures and values within the mediasphere.

Language for example is often perceived as a window to culture; these two realms are inextricably intertwined and symbiotically dependent (Heath, 1983; Gutierrez \& Larson, 1995). Yet we find that much media is channeled through few and dominant languages, undermining a vast and linguistically diverse populace. Also, the portrayal of marginalized groups is troubling given that often their cultures and values are skewed and biased in the media, cultivating stereotypes and misinformation (Harris, 2009). For cultural, linguistic, and technological equity to occur, learners need to actively participate in the construction of their knowledge domains. In 
doing so, the main issue of study becomes as Vries (2003) explains, how different representations can support different learning interactions. In other words, the question he poses as key to the shaping of pro-social media is which type of representations present affordances for what kinds of empowering interactions? Thereby, this paper investigates the socio-cognitive implications of the folksong karaoke product on pedagogic and socio-cultural values through a range of educative, cultural, entertainment and multimodal features. We first look into the background of this project and product and the results from its pilot studies, before going into the socio-cognitive dimensions that this product offers and its potential for social change. This paper demonstrates how media empowerment can be enabled through a karaoke edutainment product and can serve as a guide to development communication actors when deploying information and communication (ICT) tools to enhance engagement.

\section{The Birth of the Folksong Karaoke Project}

This folksong karaoke product builds on the Same Language Subtitling (SLS) initiative that won the World Bank Development Marketplace award in 2002 and the Tech Laureate honor from the Technology Museum of Innovation in 2003. The SLS concept for literacy was conceived in 1996 by Dr. Brij Kothari, professor at the Indian Institute of Management-Ahmedabad (IIM-A) and the founder of Planet Read, the non-profit agency executing the folksong karaoke product with Hewlett-Packard funding. The SLS feature entails leveraging on popular film-based entertainment programming on television by applying subtitles in the same language to enhance reading experiences among neo-literates. The subtitles change color to match the audio track exactly so that even a non-literate person is able to identify the word being sung at any given time. 
Almost ten years later, the enormous impact of this simple and low-cost initiative on literacy has become a recognized phenomenon through accumulated empirical evidence over the years (Arora, 2006; Kothari 1998; Kothari et al., 2002). The correlation of SLS with reading improvements and audience preference of subtitled over unsubtitled songs has been established (Kothari \& Takeda, 2000). Furthermore, the role of SLS in enhancing entertainment has been demonstrated with literacy being achieved incidentally (Kothari, 2000). However, amidst this success have emerged reservations on using film-based content for education, "the battle against 'filmi culture' on moral grounds has proven to be a major stumbling block for some policy makers" (Kothari \& Takeda, 2000, p. 137). In 2001, an agreement was made between Doordharshan, the national television station in India and IIM-A to apply subtitling on folksong programming recorded in-house. Results showed that even though film-song programs gained a higher viewership than folk-song programs, the folksong lyrics became more widely used and displayed openly by people in schools and homes (Kothari, Pandey \& Chudgar, 2004). In fact, with little publicity, this folksong project raised about 50 per cent of the telecast and SLS expenses from advertising revenue. This positive outcome gave birth to the folksong karaoke project in Andhra Pradesh, attracting funding from Hewlett Packard.

\section{Same Language Subtitling and Impact on Reading Skills: Key Findings}

Having won the World Bank Development Marketplace Award in 2002, SLS has picked up serious media attention at the national and international level. The New York Times (2003) declared this as "one of the most cost-effective ideas...such subtitles could be used worldwide to increase literacy and cost almost nothing." Bill Clinton (Realini, 2011) in a public address at a Clinton Global Initiative event enthusiastically endorsed this effort by calling it a "small thing 
that has a staggering impact on people's lives." There have been numerous articles, interviews and awards since its inception in 2002 including from Stanford University, Google and the Ashoka foundation. That said, behind this media frenzy lies some serious and longitudinal research that does establish its positive impact on reading, especially amongst neo-literates.

Kothari and team conducted several impact studies as well as commissioned an independent study by Nielsen's ORG-Centre for Social Research (1999) to measure the effects of SLS on literacy over five years. The primary goal was to target neo-literates, those who are likely to drop out of school due to socio-economic reasons and thereby in danger of losing their literacy skills. This initiative is based on the fact that about 60 per cent of the youth, particularly girls drop out in secondary school (UNICEF, 2009) and will most likely not be exposed to the printed text given the dearth of libraries and printed material in rural areas. This combined with the fact that Indians regardless of their socio-economic position are inherently a film-loving demographic, and with a majority having access to a television set, makes an interesting platform to sustain literacy practices. A case in point is that Bollywood, the world's largest film industry produces about a thousand movies a year, and the dominant content on Indian television is Bollywood music videos, averaging about five-thousand per year (Kumar, 2008). With subtitling added to these music videos, it leverages on popular media and television practices for positive gains in literacy.

The SLS initiative primarily targeted the 300 million neo- literates with the goal of transitioning them to functional literacy through lifelong reading practice. In 2002, SLS was added to Rangoli, a nationally telecast program of Hindi film songs. Nielson used a baseline measurement of the reading skills of a randomly drawn sample of 13,000 neo-literate people in 2002. The reading skills of the same sample were re-measured by the exact same reading tests 
post SLS exposure through Rangoli programming. Purely from schooling and without any exposure to SLS, it was found that 24 per cent children became good readers after 5 years of schooling. But in the group of school children that was exposed to SLS, 56 per cent became good readers. Conversely, in the no-SLS group, 25 per cent children remained illiterate even after 5 years of schooling. While in the SLS group, 12 per cent remained illiterate. Another finding that emerged was that SLS was preferred for song-based programming by 90 per cent viewers.

Furthermore, eye-tracking research was implemented, showing that viewers naturally synchronized the auditory and textual information while watching a film song with SLS. When SLS was integrated into popular television-based entertainment, reading happened automatically and subconsciously. These impact studies concluded that for every US dollar spent on subtitling a nationally telecast program of Hindi film songs, it gave 30 minutes of weekly reading practice to 10,000 people for a whole year. Based on these impact studies, it became established that

1. Reading becomes automatic and subconscious in everyday entertainment through SLS

2. Bollywood music videos due to their popularity and repetition of lyrics enhanced reading skills through increased print exposure, educating and entertaining neoliterates at the same time.

Overall, SLS is found to be a cost effective and simple measure to produce high gains in literacy through popular music videos, especially amongst neo-literate children. However, much focus has been on the skills of reading, with little attention to its actual content and socio-cultural impact. Given the policy backlash to using Bollywood music videos for learning, the folksongs project has been viewed as a strategic means to expand the benefits of SLS by making reading 
not just instrumental but meaningful. More importantly, it is allowed to enter the school system due to its acceptable content and serves as digital content for the newly acquired computers in schools in rural areas of India, a parallel initiative that seeks to create connectivity to all rural schools in the next decade (Arora, 2006a). This paper, based on preliminary positive findings from a pilot test of the folksongs karaoke product in schools, goes onto analyzing its possible socio-cognitive implications on pedagogic and socio-cultural values of the rural consumer. The goal is to be able to aid development agencies in the designing and shaping of edutainment digital content by investigating the socio-cognitive affordances and constraints of this product.

\section{Product Description}

The folksong karaoke product ventures to create meaningful literacy through the revival and proliferation of popular regional folksongs with social awareness themes in disadvantaged settings. With sponsorship from Hewlett-Packard, Planet Read created its prototype Internet/CDROM based jukebox of SLS folksongs in rural Andhra Pradesh, India. Its social awareness themes ranged from child labor, education, farmers plight, women's empowerment, dowry, HIVAIDs to caste segregation. The folksongs were chosen based on extensive surveys of local folk preferences and grassroots research with activists and artists within the vicinity. Popular local folksingers were recorded professionally. Photographic stills of the local village environment with locals as actors were captured to visually represent the lyrics of the songs. Consumers can view and sing along with the songs in karaoke fashion, with SLS getting highlighted at the bottom of the screen in tandem with the audio file. This is meant to not just enhance reading skills of neo-literates through the already proven SLS method, but also create emotive bonding, increase socio-cultural awareness, and shape values through the folksongs content. 


\section{Pilot Testing of Product}

The positive impact of SLS on reading skills has already been established over the last decade. However, all impact studies of SLS on reading have been outside the classroom, particularly in informal social settings. Also, these studies have tested SLS applied mainly to popular filmmusic videos (Bollywood for example). However, few studies have investigated the implications of applying SLS to rural folksongs, in particular, within a school setting. Arora has published some studies on this matter concerning the trade-offs that ensue in negotiating localism with scalability when digitalizing and indigenizing cultural content (2006). Further in another study, Arora analyzed the impact of this product on girl's perception and usage of new technology in rural India (2006b). What was found was that by linking folksongs with computers, it opened up opportunities to shape, transform and/or (re)configure spaces for and by girls in rural India through interaction with technology in ways that are meaningful to them. However, there are no studies that delve into this product's socio-cognitive implications, especially within a school setting.

Therefore, the purpose of this pilot is to analyze the response to the localization and enculturation of content mediated by the SLS feature within a rural classroom environment. More specifically, this paper applies a socio-cognitive lens to gauge the affordances and constraints of this product in areas of engagement and empowerment. After all, can we truly assume that rural demographics prefer their local folk content over popular film music videos? What are the possible user preferences (teachers and students) of such local content compared to film content and why? Does this product enhance reading skills or take away from the functional aspect by focusing too much on the meaning of content? Will such pro-social content help facilitate a shift in values and beliefs amongst students? To reiterate, this paper focuses on the 
effects this product has on engagement, empowerment and enculturation of children within an educational setting.

We demonstrated the folksongs karaoke product across eleven schools, (all sixth graders; ages $11-12 ; \mathrm{n}=405$ ); five private and six public in Kuppam, a village constituency in rural Andhra Pradesh, India (Table 1). English is the medium or co-medium of instruction for private schools in this area while government schools teach in Telugu, the regional language, for instruction. According to the Kuppam Area Development Authority (KADA), 90 per cent of the government school children are from backward castes and scheduled and tribal castes while 61 per cent of private school demographics come from these marginalized groups (2005). The boys outnumbered the girls in both private and public schools: 57 per cent in government and 62 per cent in private schools. We chose these schools within this area due to their access to computers as this folksongs product can serve as supplemental digital learning material for such classrooms. After all, e-learning initiatives have been spreading across the so-called developing world, wherein several governments are deploying ICTs to narrow the digital and e-learning divide.

We showed both, the folksongs and popular current film songs with the SLS feature as well as film-songs without the SLS feature. We asked the children their overall enjoyment preferences. We conducted these demonstrations within the school's computer lab setting. First, we found that a majority of children expressed preference for songs with the SLS feature over songs that did not provide it. This corroborates with prior findings on SLS wherein the audience expressed desire to view the lyrics simultaneously as they could follow the songs better (Kothari et al., 2004). Secondly, a higher percentage of children claimed to enjoy folk over the cinema CD-ROM. They stated preference towards specifically the mother-child relationship songs, devotional, and environmental songs. In interviews with the teachers, they expressed a strong 
bias towards folk over film material, as they considered cinema content risqué and inappropriate in school settings. When asked how they could integrate folksongs content into their curriculum, they suggested that it would be most appropriate to use during moral science classes and cultural activities (Table 1). While undoubtedly this data is relatively sparse, it does encourage us to pursue efforts in localization of digital content, especially for rural schools in developing countries. These preliminary positive findings create sufficient basis to go deeper into analyzing the range of socio-cognitive implications on engagement, empowerment and education of our young consumers of such content.

\section{Socio-Cognitive Implications of Folksongs Karaoke Content on Learning}

According to Bandura's (1986) classic social-cognitive theory, psychosocial functioning is a triangulation of personal, behavioral and environmental "interacting determinants that influence each other bi-directionally" (in Bryant \& Zillmann, 2002, p.121). This theory is rooted in the agency perspective, viewing people as self-reflecting and self-regulating entities and as "producers as well as products of social systems" (p.124). In taking this approach to analyze these preliminary positive findings, it allows us to focus on both the social and the individual dimension, important when deliberating on pedagogic content and its potential to shape sociocultural values. In the forthcoming section, we specifically investigate this product along the lines of (I) Engagement and (II) Empowerment, two essential dimensions that contribute to making digital literacy content effective and transformative in people's daily lives. 


\section{Folksongs Karaoke for Engagement}

In current times, it is well accepted that it will no longer suffice to provide mere information for learning. The youth regardless of geographic or socio-cultural contexts expect to be engaged and entertained, especially when it comes to digital content where the bar is raised given the abundance of information within the virtual sphere. In this case, several challenges and concerns surface as decisions are made in the design of this content for maximizing effectiveness. Also, given the positive preliminary findings from the pilot study on user preferences, it is worth investigating its possible socio-cognitive implications on learning. In the upcoming section, this is addressed along the following dimensions: a. Multi-sensory cognition: this section grapples with the degree of multimodal stimulation this product offers and its impact on acquiring reading skills. Questions addressed here are on whether visual-stills versus the motion-format is more effective in learning and what is the role of repetition and redundancy in human information

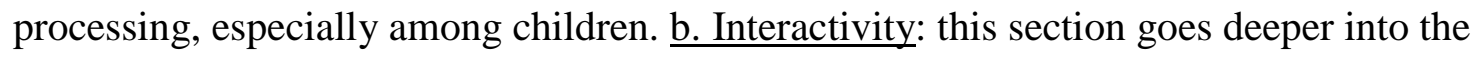
understandings of interactivity and its role in collaborative literacy development. Here, the SLS karaoke format is shown to allow for group learning. c. Contextualizing content: this section sheds light on children's preferences for folksongs over film music videos, attributing to localization and familiarity and the overall symbolic connotations folksong videos have for this audience. Here, digital representations and productions of the local context and its effects on

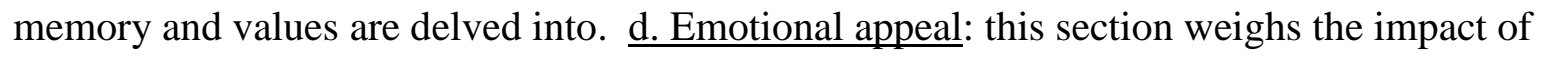
emotions on learning and how symbolic representations can lead to change in mindsets.

\section{a. Multi-sensory cognition}

There is a fine balance between enhancing stimuli in learning materials for augmenting engagement versus over-stimulus, creating a disjuncture in cognitive processing. In this product, 
there is deliberate redundancy instilled in the folksongs recorded through repetition of certain stanzas and usage of photographic stills. Both, for budget reasons and to prevent overstimulation, the visuals are in stills and not motion format, unlike film-music videos. Here, the audience sings along with the SLS text highlighted at the bottom of the screen simultaneous to the audio and visual stills flow. This strategically combined visual-textual-auditory redundancy facilitates comprehension. It is seen as cognitively beneficial to present verbal, visual and audio information as a unified source. Gyselinck and Tardieu (1999) states that, “...the concurrent presentation, as compared to the presentation of only one form of information tends to lead to an increase in performance on memory and comprehension" (p.11). This encourages the participant to hold more information in each working memory, reducing the processing load. It is essential to keep in mind that in this multimedia format, there is a rich representation of social and cultural symbols that manifest through the confluence of text, audio and visual media streams. These representational 'languages' integrate to expand human processing systems (Thompson, 1980).

Even the separation of mediums has the capacity to influence cognition positively. For example, taking the constructivist approach, the mind is seen as active in its reception to music (Serafine, 1984). The human processing system constructs its perceptions through interaction with the art form. Parallel findings exist in the visual cognitive domain. The role of imagery on concept acquisition among lower socio-economic status (SES) children has been documented in a classic study by Dixon and Saltz (1977). It was found that high imagery stimuli facilitated learning of perceptual concepts among SES children.

Alternately, studies have shown that there is a positive correlation between comprehension of a story read from a book or through radio but less so when seen on television (Harris, 2009; Pezdek \& Stevens, 1984; Subrahmanyam \& Greenfield, 2009). Based on these 
findings, it has been suggested that skills for extracting information from television are different from those used to extract information from radio or print. However, this folksong karaoke tool can challenge this precept through its innovative use of text within its multimedia format. Its usage on television/computers blurs the distinction in information processing and comprehension between old and new media forms. Through this tool, the computer can become an electronic book for collaborative class learning. Over the years, several studies have shown positive and incidental learning of reading through subtitling on television (d'Ydewalle et. al., 1991; Kothari, 2004; Neuman \& Koskinen, 1992). What is needed is to extend these benefits through meaningful content and deliberately apply SLS to digital content as in the case of the folksongs karaoke content.

\section{b. Interactivity}

According to Fortin (1997), interactivity implies the shift from unidirectional communication pervasive in traditional media to interchangeable roles of senders and receivers with contemporary media. The level of interactivity is determined by the degree of control of the end user. Several researchers have explicated on the varied dimensions of interactivity within media forms. According to Mundorf and Laird (2002), they distinguish interactivity by certain characteristics: (1) the degree of selectivity, (2) the degree of control on modification of content by the end user, (3) the quantity of different content that can be selected and modified, (4) the degree of linearity/ non-linearity and (5) the degree of multi-sensory activation while using the media. In this product, selectivity is determined by the choice of folksongs by the user, as well as the subtitling script preferences (in the case of the prototype CD-ROM, it is the Roman and Telugu script). Additionally, the user can pause, stop, rewind and fast-forward the song of choice 
if the product is mediated through the computer. Users can also manipulate the pace of the song to suit their reading level. The quantity of songs is however limited given the current budget.

Interestingly, the unique feature of SLS as applied in this tool can help create group literacy due to shared media consumption among users. This extends the definition of interactivity from the conventional single user to the medium to one where there are multiple users for a single medium. Contrary to historical social implications of reading as a socially isolated activity (Olson, 1994), the text medium within this karaoke form demands a shared audience. This is due to its demographic target wherein there is limited media access, be it televisions or computers (Wilburg, 2003). In the testing of this product, about 25-30 children were able to participate in one sitting. Teachers showed a penchant for using this tool for group cultural activities in the classroom where literacy development was an incidental by product.

\section{c. Contextualizing content}

Findings on the preference of folk over cinema songs were revealing. Despite the folk being of lesser professional quality than the film CD-ROM, and the folk's usage of stills versus the film CD-ROM's motion picture format, a higher percentage of the children expressed their bias towards folksongs karaoke (Table 1). When asked why, they stated several reasons: familiarity with the song so they could sing along, excitement of seeing their village portrayed in a picturesque manner, and that the songs reminded them of home. They expressed excitement in seeing their local environment portrayed in a digital format of commercial quality. Some recognized individual actors in these music videos, making it more enjoyable for them. These music videos were shown multiple times to mitigate the novelty factor.

These responses can be explained in part through the contextual lens of cognition. According to Jacob (1997), context is central to cognition. She outlines the historical perspective 
of context in understanding cognition; prior to the 1960s, cognition was studied as a universal, context-free process. She further states that even today, few scholars examine the contextual and cultural impact on cognitive activity. She recommends that by recognizing the contextual influences on teachers and students alike, education innovations would be adapted at a faster pace: “...instead of ignoring context, teachers would be better off focusing on it to adapt the new products based on their environment to maximize the innovations" (p.6). Thereby, in viewing the findings through this lens, it can be argued that local representations such as photographic stills of the villages and its people, of folksongs they grew up with, and socio-cultural themes pertinent to their locality can resonate with this audience and contribute to furthering engagement.

After all, context does not merely allude to the environment of concern. It encompasses representations and symbolic portrayals of groups, their cultures, attitudes, and practices. If harnessed in a meaningful and innovative way, this can positively alter cognitive processing (Goodnow, 1990; Saljo \& Wyndhamn, 1993; Zhang, \& Patel, 2006). Today it seems appropriate to treat societies and communities not as unified wholes but as arenas where many forces with differing interests are enmeshed. Yet, dominant media and curricula do not sufficiently reflect this diverse view (Bryant \& Zillmann, 2002; Harris, 2009). Several factors contribute to this disturbing trend of media tunnel vision. For instance, McLeod, Kosicki, and McLeod (2002) explicate that some of the reasons for content conformity is due to the attempt to pander to a wider audience, heavy reliance on routine news sources, hegemony of content producers from select groups and concentration of media ownership. They suggest that to gain citizen activation, the feelings of less involved citizens need to be articulated by transforming them into more organized views. Substantiating this, Harris (2009) brings to light current media's tendency to 
make invisible certain groups and their cultures as well as negatively portray groups through stereotypes, depriving large populations of a fair media depiction. Hence, educational multimedia not only needs to represent an eclectic set of groups and individuals, they need to proactively construct the images of historically marginalized groups.

This pro-social construct can have a positive impact on socio-cognitive functioning through generation of high levels of confidence, cultural pride, positive social skills, attitudes and interpersonal cooperation (Greenberg, 1982; Harris 2009). However, in order to shape new multimedia for learning, it is important to understand the workings of the mind. As is now commonly understood, the mind utilizes schemas for cognitive processing of information (Trenholm, 2010). This concept refers to knowledge frameworks that structure an individual's memory for people and events. Thereby, people interpret media according to their prior knowledge and beliefs and the context in which the message is received. It is important to keep in mind that much of the content for schemas is culture-specific. Hence, by drawing on the local elements, the folksongs karaoke product with its pictographic stills of village settings, the recording of local popular folk artists, and usage of folk music has the ability to enhance cognitive functioning amongst a vast and underrepresented public. As Kreuter, Strecher \& Glassman (1999) aptly put it, "tailor-made communications are viewed as more relevant and credible, are better remembered and are more effective in influencing behavior than general messages" (p. 278).

\section{d. Emotional appeal}

Cultural symbols often evoke strong emotional feeling in the participant. As Harris (2009) elucidates, these symbols affect one's individual psychological well-being and deep-seated personal needs. The closer the association of the folksongs karaoke content with positive 
emotions, the more successful the product is likely to be. This product captures highly emotive events and themes through folksongs. It encapsulates complex relationships among people and their surroundings and reverberate themes of people's connection with land, family ties, religion, and social/ caste hierarchies. Harris (2009) states that, "influencing emotions is often the best first step to influencing beliefs, and ultimately behavior" (p. 147). These emotive symbols are

often used successfully in advertising and media in general. However, if harnessed appropriately for pro-social and educational purposes, they can positively impact cognitive processing amongst our target audience.

Overall, this first section on engagement covers a range of multimodal and technical features of this product that capitalize on the socio-cognitive understandings on stimulation and comprehension, interactivity and collaborative learning, contextualization and its symbolic resonance on meaning-making and emotions and its impact on learning.

\section{Folksongs Karaoke for Empowerment}

Historically, construction of educational content has been strategically designed to shape mindsets and behavior. However, the nature of content has been often structured according to the dominant forces in society, creating norms that exclude several groups of people and cultures. In this section, we seek to address how this folksongs karaoke product can include and possibly empower marginal groups through the usage of meaningful content. In the upcoming section, this is addressed along the following dimensions: a. Digitalizing folksongs for socio-cultural change: this section goes into understanding the role of folksongs in society and its potential for social activism. Here, embedded pro-social messages are analyzed in relation to behavior

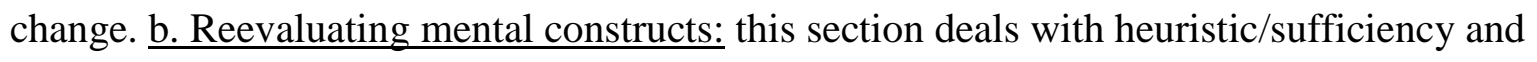


accessibility principles in shaping judgment and the role of information in this process. Further, it reveals how mental constructs can be shifted through the pro-active usage of meaningful symbolic imagery and events embedded in content. c. New scripts for action: this section addresses alternative schemas for positive representation of marginalized demographics and its symbolic capabilities in shaping new mental scripts.

\section{a. Digitalizing folksongs for socio-cultural change}

Folk have been largely perceived as that which is bucolic, bounded, and unchanging (Narayan, 1993; Trilling, 1971). Yet folklorists have amassed compelling evidence to construe 'folk' as more three-dimensional, non-homogenous and dynamic where they do in fact respond to the current social and cultural milieu (Appadurai, 1991; Arora, 2006, 2006a; Manual, 1998;

Narayan, 1993). Naithani (1996) writes about the politicization of folk across centuries, tracing the historical roots of folk to modern times. She expounds on the current trends of folk being used for political and social activism. For example, Gaddhar is a Marxist and folk activist who is part of the Peoples War Group (PWG) in Andhra Pradesh. He moves from village to village singing folksongs on oppression and inequality among the rural populace. His high popularity among the villagers has driven the Andhra police to put a bounty on his head. However, folksongs can also be used as a tool servicing a government agenda. There has been several prosocial efforts by the government in using folksongs to influence behavior in health, education, sanitation and other social issues over the years, asserting its power to shape people's thinking and behavior (Arora, 2006).

In digitalizing folksongs, there are valid concerns about its authenticity when altering folk symbols for pro-social means. We cannot assume that the values conveyed through this multimedia form are received in a similar manner (Greenfield \& Cocking, 1996). Thus, the 
question is, can and should folk media carry modern messages? According to Lent (1980), folk media are better carriers of pro-social messages than artificially construed themes emanating from the state. He argues that in spite of the trade off in folk authenticity where folk imbues modern messages, it is still a preferred non-colonial media form for change. Most current media is unidirectional, a one-way flow of information from urban to rural. With folk media he espouses, there will be a more varied ideological representation by employing folk symbols that are readily comprehensible and accessible to disenfranchised populations. Ginsburg (1991) concurs and points out to the challenges involved in the creation and dissemination of folk media. She examines the Faustian dilemma of gaining widespread portrayal of underrepresented groups while at the same time being at risk of losing their original cultural intent. Yet, against these odds, she still recommends indigenous media as “... a possible means- social, cultural and political for reproducing and transforming cultural identity among people” (1991, p.92). Thereby, this product employs contemporary and at times socially taboo messages such as HIV/AIDS, domestic violence, caste segregation and dowry within its popular folksongs format. However, the key to making this product embraced across demographics is in its focus on entertainment, with literacy and social reform being incidental.

\section{b. Reevaluating mental constructs}

Shrum (2002) links stimuli with response to explain social cognition. She elaborates on two principles underlying social cognitive research. The first principle, Heuristic/ Sufficiency principle concerns with the type of information retrieved for constructing judgment. The Accessibility principle on the other hand concerns itself with the role of gathering information in constructing a judgment. She also explains the cultivation effect wherein people do not give much thought to their judgments when processing information. As Shrum states, "it is 
remarkable as to how little information is used in the course of constructing judgments and how often heuristics are employed" (p.90). In fact, it is seen that when people make judgments, they tend to use the constructs that are most readily accessible from memory.

Unfortunately, current media distorts and skews information and representation of large groups of people and cultures. Hence, media has a responsibility in diffusing pro-social material to cultivate positive mental constructs of underrepresented groups. Harris (2009) suggests that in doing so, it is conducive to focus on specific behaviors that the audience may change than a general aim to change attitudes. For example, the folksongs karaoke product is broken down into specific themes of caste segregation, gender inequity and HIV/ AIDS. For these folksongs to have a deeper impact, it is essential to choose a folksong with a specific narrative, a context, or an issue within these larger themes. For instance, 'Kantiki Katukapetti,' a popular dowry, mother-child folksong, got the highest ratings in enjoyment amongst the children (Table 1). This song captures a conversation between the mother and the daughter. The daughter reminiscences on their early days together where the mother would pamper her by putting flowers in her hair and would smother her with kisses. But now the daughter laments, she is married and her in-laws beat her regularly because the dowry is not sufficient. This song holds resonance across India where the practice of dowry even though outlawed, still prevails for the most part and early marriages in rural areas are a common phenomenon (Buncombe, 2011). Hence, folk music with specific content can give emotive depth to underrepresented issues and peoples, and can prime positive images to counteract stereotypes influencing judgments and intentions. Further, in the context of schools, it can be used as a starting point by teachers for further discussion on these complex issues that would otherwise have no easy place in day-to-day conversation with these youth. 


\section{c. New scripts for action}

Existing media narratives often fail to address important issues and concerns of the disenfranchised. Altering schemas is not sufficient to provide positive representations of the underrepresented populace. Often what are needed are new scripts for action. As defined by Harris (2009), a script is a mental step-by-step response guide for action that helps people deal with the problematic situation at hand. Certain stimulus activates certain scripts for behavior that is closely related to the mental constructs/ schemas as extrapolated earlier on. People are constantly learning scripts from popular media outlets. For example, a television show can teach the audience on how to deal with topics such as rape, incest, and murder. The symbolic capability of these scripts should not be underestimated: "it is with symbols that people process and transform transient experiences into cognitive models that serve as guides for judgment and action...through symbols, people give meaning, form, and continuity to their experiences" (Bandura, 2002, p. 95). For example, 'Jum Jum Taaraare,' a song on women solidarity can be empowering through the harnessing of visuals of women holding hands and lyrics signifying women's unity through collective action. Furthermore, Bandura alerts us to the sculpting of public consciousness through electronic acculturation using symbols from the local environment. However, for the vast population, there are few media scripts of choice pertaining to deeply prevalent and at times taboo issues in their domain. For example, in several parts of Africa and Asia, the media is for the most part silent about HIV/AIDS (ActionAid, 2006). However, with the folksong karaoke format, new scripts can be created within the safety of the folksongs and education arena, combining entertainment with empowerment. 
Overall, this second section on empowerment covers a range of symbolic and representational aspects embedded in this product that can lead to shifts in new schemas, scripts and overall socio-cultural change.

\section{Conclusion}

The folksongs karaoke tool can be an engaging and empowering tool for diverse demographics by catering to a wide range of causes: cultural revitalization and proliferation, literacy, health, and gender equity. While the initial intent to target children in rural areas through folksongs limits its scaling of content across varied environments, its ability to assimilate eclectic concerns within the same CD-ROM allows for a healthy cross-issue engagement within a complex and rich contextual environment. Its focus on entertainment can facilitate engagement and possible higher levels of scaling across settings. However, there are some significant challenges in the dissemination of this multimedia tool across contexts. Budgets are limited for global scaling which leaves folk media largely invisible and economically fragile. Furthermore, transference can be formidable as narrative contexts may not be represented abstractly enough to adapt and transfer to new contexts. According to Fisch (2002), for a successful transfer to occur, there needs to be the following: a rich understanding of the subject matter, an abstraction of the content beyond its original context and a linkage between the presented symbols and the new situation to which it needs to be applied. He suggests that the optimal solution may lie in presenting the same educational content in several different narrative contexts instead.

The other issue of concern is misappropriation of context and cultures. This product, in spite of the involvement of the community in its production, is still controlled by the biases of the production team. The team makes the key decisions of which folk artists to choose from, the 
recording of the music and the final assemblage of the product for consumption. As Bandura (2002) states, if the consumers "are not the actual agents of their actions, they are spared selfprohibiting reactions" (p.94). Hence, agency needs to be expanded to encompass participation not only in product creation, but also dissemination. In fact, this product does not need to be limited to folksong content. This multimedia format could be used to generate original content designed and executed by disenfranchised groups. This enables the 'invisible' majority a contemporary, active voice in self-representation.

But the hardest part is the actual alteration of mental constructs through new schemas and scripts. In spite of the pro-social nature and positive symbolism embedded in this multimedia tool, it is still a gargantuan challenge to change old mindsets. To make a long lasting positive impact on mental frameworks to influence behavior, there needs to be systemic involvement and commitment in the creation, dissemination and scaling of this format across schools, communities, non-profit institutions, think-tanks, academic and government bodies. As Bandura (2002) aptly puts it, "people do not change from week to week what they regard as right or wrong or good or bad...after they adopt a standard of morality, their self-sanction for actions that match or violate their personal standards serve as regulatory influences" (p. 124). However, through long-term commitment and sensitizing to local parlance and diverse voices, the folksong karaoke tool can function as a new breeding ground for alternative thought and action. Overall, what is transferable here in this study are the lessons learnt in the shaping of such digital content and its range of affordances and constraints in the socio-cognitive domain that allows development actors, policy makers and funders to weigh their options and proceed accordingly. Word Count: 8078

Acknowledgement: The production of the SLS folksongs project has been a team effort. I would like to thank PlanetRead's team: P.S Jayamma, Amit Dixit, Maya Sukumar, Nirav Shah, K.T. 
Pauly, and Ashok Joshi. We wish to thank Hewlett-Packard for funding and supporting this project. I am particularly grateful to the founder of PlanetRead, Dr. Brij Kothari for his mentorship in this process. I would like to pay tribute to the local Kuppam government office that provided access to Kuppam education and development data and to the Kuppam community at large for being tremendously helpful and inspirational in this project. Last, but not least, I would like to emphasize P.S Jayamma's invaluable role in this project. Due to her drive, local credibility and dedication, we were able to take this project to a much higher footing. Her efforts in this project have been deeply felt.

\section{References}

ActionAid. (2006). The sound of silence: Difficulties in communicating on HIV/AIDS in schools. Retrieved on January 282012 from website: http://www.ibe.unesco.org/uploads/media/HIV_AIDS_187_06.pdf

Arora, P. (2006). Karaoke for social and cultural change. Information, Communication \& Ethics in Society, 4(3), 121-130.

Arora, P. (2006a). The ICT Laboratory: An analysis of computers in schools in rural India, Association for the Advancement of Computing in Education Journal, 15(1), 57-72

Arora, P. (2006b). E-karaoke for gender empowerment. Presentation and published proceedings at the Information and Communication Technologies and Development (ICTD) International Conference 2006, University of Berkeley: CA.

Appadurai, A. (1991). In gender, genre and power in South Asian expressive traditions, University of Pennsylvania press, Philadelphia.

Bandura, A. (1986). Social foundations of thought and action: A social cognitive theory. Upper Saddle River, New Jersey: Prentice Hall.

Bandura, A. (2002). Social cognitive theory of mass communication. In Bryant, Jennings \& Zillmann's (Eds.) Media effects. Second Edition, pp. 121-153, New Jersey: Erlbaum.

Buncombe, A. (March 2, 2011). Dowry wars: The big issue that has India divided. The Independent, Retrieved on January 28, 2012 from website:

http://www.independent.co.uk/news/world/asia/dowry-wars-the-big-issue-that-has-india-divided$\underline{\text { 2229498.html }}$

Carvin, A. (2000). More than just access: Fitting literacy and content into the digital divide equation. Educause Review, 35(6), 38-47.

Cocking, R. R., \& Greenfield M. P. (1996). Effects of interactive entertainment technologies on children's development. In Cocking, R. R. \& Greenfield M. P.'s (Eds.) Interacting with video, pp. 3-8, New York: Ablex. 
Dixon, D \& Saltz, E. (1977). The role of imagery on concept acquisition in lower-SES children. In Child Development, 48(1), 288-291.

Fisch, M.S. (2002). Vast wasteland or vast opportunity? Effects of educational television on children's academic knowledge, skills, and attitudes. In Bryant, Jennings \& Zillmann's (Eds.) Media effects. Second Edition, pp 397-427, New Jersey: Erlbaum.

Fortin, D (1997). The impact of interactivity on advertising effectiveness. Doctoral Dissertation, University of Rhode Island, Kingston.

Ginsburg, F. (1991). Indigenous media: Faustian contract or global village? Cultural Anthropology, 6(1), 92-112.

Goodnow, J. (1990). The socialization of cognition: What's involved? In Stigler, Shweder \& Herdt's (Eds.) Cultural psychology: Essays on comparative human development, pp. 259-286, New York: Oxford University Press.

Gutierrez, K., \& Larson, J. (1995). Script, counterscript, and underlife in the classroom: James Brown versus Board of Education. Harvard Education Review, 65 (3), 445-471.

Gyselinck, V, \& Tardieu, H. (1999). The role of illustrations in text comprehension: What, when for whom and why? In Goldman, S.R, \& Oostendorp, V. H.,'s (Eds.) The construction of mental representations during reading, pp. 5-16, Mahwah, New Jersey: Erlbaum.

Gyselinck, V, \& Tardieu, H. (2003). Working memory constraints in the integration and comprehension of information in a multimedia context. In Oostendorp, V. H.,'s (Ed.) Cognition inadigitalworld, pp. 3-25, New Jersey: Erlbaum.

Harris, R. (2009). A cognitive psychology of mass communication. (Fifth Edition): New Jersey: Erlbaum.

Jacob, E. (1997). Context and cognition: Implications for education innovators and anthropologists. Anthropology and Education Quarterly. 28(1), 3-21.

KADA. (2003). Private and public school statistics in Kuppam. Kuppam Area Development Authority. Andhra Pradesh Education Department.

Kothari, B, Pandey, A., \& Chudgar, A. (2004). Reading out of the idiot box: Same language subtitling on television in India. International Technologies and International Development, 1(3), 23-44.

Kothari, B., Takeda, J., Joshi, T., \& Pandey, A. (2002). Same language subtitling: A butterfly for literacy? International Journal of Lifelong Education, 21(1), 55-66. 
Kothari, B, \& Takeda, T. (2000). Same language subtitling for literacy: Small change for colossal gains. In Bhatnagar, S.C. \& Schware, S's (Eds.), Information and communication technology in development, pp.176 - 186, World Bank Institute, New Delhi: Sage Publications.

Kothari, B. (2000). Same language subtitling on Indian television: Harnessing the power of popular culture for literacy. In Wilkins, K's (Ed.), Redeveloping communication for social change: Theory, practice and Power, pp. 135-146, New York: Rowman \& Littlefield.

Kreuter, M. W., Strecher, V., \& Glassman, B. (1999). One size does not fit all: The case for tailoring print materials. Annals of Behavioral Medicine, 21, 276-283.

Kumar, S. (2008). Global Bollywood: Travels of Hindi song and dance. University of Minnesota Press.

Lemke, C., \& Coughlin, L. (1998, July 10). Technology in American schools: Seven dimensions for gauging progress. Milken Exchange. Retrieved January 28, 2012 from http://www.mff.org/publications/publications.taf?page-158

Lent, A.J. (1980). Grassroots renaissance: Folk media in Third World nations. Folklore, 91(1), 78-91.

McLeod, M. D, McLeod, M.J, \& Kosicki, M.G. (2002). Resurveying the boundaries of political communications effects. In Bryant, Jennings \& Zillman's (Eds.) Media effects. Second Edition, pp. 215-267, New Jersey: Erlbaum.

Mundorf, N, \& Laird,K.R. (2002). Social and psychological effects of information technologies and other interactive media. In Bryant, Jennings \& Zillman's (Eds.) Media Effects. Second Edition, pp. 583-603, New Jersey: Erlbaum.

Naithani, S. (1996). Political ideology and modernization of folklore: A study of three contemporary Indian artists. Jahrbuch für Volksliedforschung, 41, 74-78.

Narayan, K. (1993). Banana republics and V. I. degrees: Rethinking Indian folklore in a postcolonial world. Asian Folklore Studies, 52(1), 177-204.

Neuman, S.B., \& Koskinen, P. (1992). Captioned television as comprehensible input: Effects of incidental word learning from context. Reading Research Quarterly, 27(1), 94-106.

Nielsen ORG-Centre for Social Research (1999): Literacy Impact studies of Planetread SLS, Retrieved on January 282012 from website: http://www.planetread.org/tv.php

Olson, D.R. (1994). The world on paper. New York: Cambridge University Press.

Pezdek, K., \& Stevens, E. (1984). Children's memory for auditory and visual information on television. Developmental Psychology, 20, 212-218. 
Realini, C. (February 8, 2011). Davos: Bollywood brings literacy to millions. Retrieved on January 28, 2012 from website http://www.huffingtonpost.com/carol-realini/davos-bollywoodbrings-li_1_b_820026.html

Saljo, R., \& Wyndhamn, J. (1993). Solving everyday problems in the formal setting: An empirical study of the school as context for thought. In Chaiklin, S \& Lave, J's (Eds.) Understanding practice: Perspectives on activity and context, 9-40. Cambridge: Harvard University Press.

Serafine, L.M., (1984). The development of cognition of music. The Musical Quarterly, 70(2), 218-233.

Shrum, J.L. (2002). Media consumption and perceptions of social reality: Effects and underlying processes. In Bryant, Jennings \& Zillman's (Eds.) Media effects. Second Edition, pp. 69-75. New Jersey: Erlbaum.

Subrahmanyam, K., \& Greenfield, P. (2009) Media symbol systems and cognitive processes. In S. L. Calvert and B. J. Wilson (eds.) The handbook of children, media, and development, Oxford: Blackwell Publishing.

Taglang, K. (2000). Content and the digital divide: What do people want? Retrieved on January 28, 2012 from http://www.digitaldivide.net/articles/view.php?ArticleID=198

The New York Times (Dec 24, 2003). The Elephant and the Chili Pepper. Retrieved on January 28, 2012 from The New York Times website: http://www.nytimes.com/2003/12/24/opinion/theelephant-and-the-chili-pepper.html

Thompson, N. (1980). Multi-media: Expanded language. The English Journal, 69(1), 87-89.

Trilling, L. (1971). Sincerity and authenticity, Cambridge: Harvard University Press.

UNICEF (2009). Literacy statistics of India: 2009, Retrieved on January 28, 2012 from the UNICEF web site: http://www.unicef.org/infobycountry/india_statistics.html

Vries, D.E., (2003). Educational technology and multimedia from a cognitive perspective: Knowledge from inside the computer, onto the screen, and into our heads? In Oostendorp, V. H.,'s (Ed.) Cognition in a digital world, pp. 155-175, New Jersey: Erlbaum.

Warschauer, M. (2003). Demystifying the digital divide. Scientific American, 289(2), 44-47.

Zhang, J., \& Patel, V. L. (2006). Electronic health records: A human project. e- Health Medical IT Solutions, Touch Briefings, 35-37. Retrieved on January 28, 2012 from website: http://www.touchbriefings.com/pdf/1965/zhang.pdf 
Table 1: Comparative Testing of Telugu folksong and Cinema songs CD-ROMs with SLS in private and government schools-(Kuppam, South India: 2004)

Preferences

Government Private

Children who preferred folksongs to cinema songs

$68 \% \quad 50 \%$

Children who preferred songs with SLS

$95 \% \quad 90 \%$

Children who preferred Telugu subtitles over English/

Roman script subtitles

Children who preferred the folksong CD to the cinema CD

Top song preference being the devotional song

$00 \% \quad 0 \%$

$86 \% \quad 62 \%$

$50 \% \quad 55 \%$

Top song preference being the child and mother song

$50 \%$

$35 \%$

Teadhers feedback on content usage in curriculum

Prime usage for cultural activities/singing competition

$45 \% \quad 80 \%$

Prime usage for language development-practice

Prime usage for moral science classes to build values

$50 \%$

$\mathrm{n}=240 \quad \mathrm{n}=165$

$\mathrm{n}=405$ children $/ 11$ schools

children/ 6 children/ 5

schools schools

